\title{
Successful clozapine re-challenge in a case of Atypical Neuroleptic Malignant Syndrome with markedly elevated Creatinine Phosphokinase and no muscle rigidity
}

\author{
Ritvij M Satodiya* and Nikhil J Palekar \\ Department of Psychiatry, Stony Brook University School of Medicine, Stony Brook, New York, USA
}

\section{Introduction}

Clozapine remains the gold standard treatment for refractory patients with severe psychotic disorders [1,2]. Neuroleptic malignant syndrome (NMS), a serious complication of neuroleptics characterized by autonomic instability, mental status changes and muscular rigidity. The atypical presentation of NMS is critical to identify and involves treatment challenges. We present a case of successful clozapine rechallenge in atypical NMS with a 400-fold Creatinine Phosphokinase (CPK) elevation in the absence of muscle rigidity.

\section{Case report}

A 30-year-old male with a history of treatment resistant schizophrenia (TRS) who is on clozapine $600 \mathrm{mg}$ daily, valproic acid $1250 \mathrm{mg}$ daily and venlafaxine XR $75 \mathrm{mg}$ daily. Three days following inpatient admission; he became diaphoretic, confused, disoriented and unresponsive to verbal prompts. His vitals and laboratory workup are mentioned in Table1. His chest X-ray and non-contrast head CT were unremarkable. EKG showed sinus tachycardia. His deep tendon reflexes were $2+$ bilaterally with no muscle rigidity, tremors, myoclonus or other focal neurologic deficits. There were no signs of trauma. He was diagnosed with NMS and transferred to ICU. He received hemodialysis for acute renal failure with elevated $\mathrm{CPK}$. We discontinued the clozapine and started I.V. fluids and bromocriptine. There was a gradual improvement in his symptoms with down trending $\mathrm{CPK}$ levels. He remained acutely psychotic and was transferred back to the inpatient psychiatric unit. Clozapine $25 \mathrm{mg}$ /day was re-introduced

2 weeks after normalizing his CPK levels. It was gradually titrated to $300 \mathrm{mg} /$ day over a period of 4 weeks. CPK levels were normal within one month. He tolerated the clozapine re-trial successfully with no elevation in CPK and improvement in his psychiatric symptoms. The final therapeutic dose of clozapine was $550 \mathrm{mg}$ /day with a clozapine level of $533 \mathrm{ng} / \mathrm{ml}$ and norclozapine level of $183 \mathrm{ng} / \mathrm{ml}$.

\section{Discussion}

Our patient had an elevated CPK with atypical NMS following clozapine treatment and it declined following discontinuation of clozapine. Other factors that can affect CPK are intense physical activity, intramuscular injections, dystonic reactions or use of physical restraints that were absent in our patient. The only absolute contra-indications for clozapine use are in cases of a prior history of clozapine induced agranulocytosis or clozapine induced myocarditis
[3]. Metlzer and colleagues found isolated increase in CPK levels with antipsychotic treatment without associated NMS [4]. The physicians should actively monitor CPK levels considering the possibility of asymptomatic rhabdomyolysis with Clozapine use [5]. Clozapine has been the most effective drug for TRS. The advantages include reduced burden of psychiatric symptoms, hospitalization, and potential need for social and occupational rehabilitation [6,7]. However, acceptance of clozapine by patients and its practice by clinicians have been hampered by apprehension regarding potential life-threatening adverse effects. The decision of clozapine re-challenge was based on following factors:

- A well-documented past history of favorable response to clozapine following failures to multiple antipsychotics.

- Absence of medical comorbidities besides obesity.

- Consensus amongst patient, patients' family and treatment team for clozapine re-trial after discussing potential risks/benefits and other treatment alternatives.

\section{- Gradual dose titration with close monitoring.}

Electroconvulsive therapy (ECT) is another safe and reasonable option in patients developing NMS on antipsychotics. The effectiveness of ECT with or without concomitant antipsychotic medications in TRS has been around $40-54 \%$ [8]. However, ECT in TRS is often limited due to higher relapse rates of $90 \%$ at 6 months following an acute ECT course unless patients continue to receive maintenance ECT along with antipsychotic medications [9]. This often presents realworld obstacles of limited availability of resources and treatment adherence.

\section{Conclusion}

Markedly elevated CPK with atypical NMS is not an absolute contra-indication for clozapine rechallenge.

We recommend to consider a thorough risk-benefit analysis and careful dose optimization and monitoring of CPK levels with clozapine re-challenge.

${ }^{*}$ Correspondence to: Ritvij M. Satodiya, Department of Psychiatry, Stony Brook University School of Medicine, Stony Brook, New York, USA, E-mail: ritvij_ satodiya@yahoo.co.in

Received: October 03, 2020; Accepted: October 14, 2020; Published: October 19,2020 
Satodiya RM (2020) Successful clozapine re-challenge in a case of Atypical Neuroleptic Malignant Syndrome with markedly elevated Creatinine Phosphokinase and no muscle rigidity

\section{References}

1. McEvoy JP, Lieberman JA, Stroup TS, Davis SM, Meltzer HY, et al. (2006) Effectiveness of clozapine versus olanzapine, quetiapine, and risperidone in patients with chronic schizophrenia who did not respond to prior atypical antipsychotic treatment. Am J Psychiatry 163: 600-610. [Crossref]

2. Lewis SW, Barnes TR, Davies L, Murray RM, Dunn G, et al. (2006) Randomized controlled trial of effect of prescription of clozapine versus other second-generation antipsychotic drugs in resistant schizophrenia. Schizophr Bull 32: 715-723. [Crossref]

3. Manu P, Sarpal D, Muir O, Kane JM, Correll CU (2012) When can patients with potentially life threatening adverse effects be rechallenged with clozapine? A systematic review of the published literature. Schizophr Res 134: 180-186. [Crossref]

4. Meltzer HY, Cola PA, Parsa M [1996] Marked elevations of serum creatine kinase activity associated with antipsychotic drug treatment. Neuropsychopharmacology 15 : 395-405. [Crossref]
5. Luckoor P, Salehi M, Kunadu A (2017) Exceptionally High Creatine Kinase (CK) Levels in Multicausal and Complicated Rhabdomyolysis: A Case Report. Am J Case Rep 18: 746-749. [Crossref]

6. Whiskey E, Taylor D (2007) Restarting clozapine after neutropenia: evaluating the possibilities and practicalities. CNS Drugs 21: 25-35. [Crossref]

7. Kane JM, Correll CU (2010) Past and present progress in the pharmacologic treatment of schizophrenia. J Clin Psychiatry 71: 1115-1124. [Crossref]

8. Chanpattana W, Sackeim HA (2010) Electroconvulsive therapy in treatment-resistant schizophrenia: prediction of response and the nature of symptomatic improvement. $J$ ECT 26: 289-298. [Crossref]

9. Sinclair DJ, Zhao S, Qi F, Nyakyoma K, Kwong JS, et al. (2019) Electroconvulsive therapy for treatment-resistant schizophrenia. Cochrane Database Syst Rev 3: CD011847.

Copyright: (C2020 Satodiya RM. This is an open-access article distributed under the terms of the Creative Commons Attribution License, which permits unrestricted use, distribution, and reproduction in any medium, provided the original author and source are credited. 